\title{
Obesidade como metáfora contemporânea: uma “Cruzada Saudável” em nome do consumo e do risco"
}

Resumo: Este ensaio remete às possibilidades de interpretação da sociedade contemporânea através da metáfora da obesidade. Apresentamos esta metáfora vinculando-a com a metáfora do "vagabundo" formulada por Zygmunt Bauman. A obesidade e o obeso são analisados como um fenômeno ambivalente, mas que contribui para compreensão de determinadas formas de exclusão social presentes na atualidade. Os conceitos de sociedade de risco de Ulrich Beck e de modernidade líquida de Zygmunt Bauman serviram como alicerce teórico desta reflexão.

Palavras-chave: Obesidade. Metáfora. Mobilidade social. Alienação social. Pós-modernismo.

\section{INTRODUÇÃO}

É recorrente nos discursos atuais que enfocam estilos de vida saudáveis a preocupação com a obesidade. O apelo e o cenário sombrio que tais propostas apontam na direção dos obesos nos serviram de inspiração na reflexão desenvolvida neste texto. A partir daí, apresentaremos a obesidade e o obeso como metáforas que se articulam com análises atuais, principalmente, através de um diálogo com as ciências humanas. Neste sentido, buscaremos outras possibilidades interpretativas destes elementos que possam apontar para além do "combate" a que estão submetidos, majoritariamente, nas ciências da saúde. Mais especificamente pretendemos com tais metáforas contribuir no entendimento da sociedade contemporânea - ressaltando aqui as articulações entre

\footnotetext{
$1 \mathrm{O}$ autor agradece as considerações e sugestões de Alexandre Fernandez Vaz, Felipe Quintão de Almeida e Julia Guivant.

* Doutorando em Ciências Humanas do PPGICH-UFSC. Docente vinculado ao Colegiado de Pedagogia da Unioeste-Cascavel. Membro do Núcleo de Estudos e Pesquisas em Educação e Sociedade Contemporânea da UFSC e de Pesquisas em Educação, Cultura, Linguagem e Arte PECLA-UNIOESTE. E-mail: ivanmgomes@bol.com.br
}

Movimento, Porto Alegre, v.12, n. 03, p. 45-71, setembro/dezembro de 2006. 
consumo, risco e saúde -, nos concentrando especialmente na abordagem baumaniana.

Zygmunt Bauman (2001) argumenta em seu livro "Modernidade Líquida" que a mobilidade é um elemento importante para se compreender as distinções e estratificações da sociedade contemporânea. Em determinado momento do livro, Bauman (2001, p. 159) remete à figura do sedentário para ilustrar uma sensação de obsolescência frente à necessidade de movimento perpétuo presente na atualidade, a qual ele caracteriza como enfaticamente voltada ao consumo. Nossa intenção é a de propor, a partir desta linha argumentativa, a obesidade como uma espécie de metáfora dos indivíduos potencialmente excluídos desta sociedade de consumo. Buscaremos, então, mostrar a figura do obeso como aquele que apresenta dificuldades em se movimentar com a leveza típica da atual fase moderna. Em outras palavras, pensaremos a obesidade e o obeso como uma forma de arquétipo da metáfora do "vagabundo", utilizada por Bauman (1999a, 1998).

Para uma melhor compreensão do leitor nos deteremos brevemente na metáfora do vagabundo. Para Bauman, na atual fase moderna - e que, como dito anteriormente, ostenta uma acentuada estratificação -, o que possibilita visualizar a capacidade de ação individual dos seus membros é o grau de mobilidade, entendida como a "liberdade de escolher onde estar" (BAUMAN, 1999a, p. 94). Neste contexto, o vagabundo ${ }^{2}$ é aquele que é empurrado pelas "forças" e "incertezas" da sociedade contemporânea ${ }^{3}$ mesmo que não queira se mover, ou então, não possui as ferramentas necessárias para se mover quando deseja tal intento. Nas palavras do autor:

${ }^{2}$ Como contraponto do vagabundo, o autor utiliza a metáfora do turista (BAUMAN, 1999a; 1998).

${ }^{3}$ Sobre estas forças e incertezas, podemos ilustrar de diferentes formas, como por exemplo, em relação aos processos de flexibilização do emprego, as ocupações e exclusões urbanas através da especulação imobiliária, bem como outros aspectos potencializados com o processo de globalização (BECK, 1999; BAUMAN, 1999a).

Movimento, Porto Alegre, v.12, n. 03, p. 45-71, setembro/dezembro de 2006. 
Esses são os vagabundos, escuras luas errantes que refletem o brilho luminoso do sol dos turistas e seguindo placidamente a órbita dos planetas: são os mutantes da evolução pós-moderna, os rejeitos monstruosos da admirável espécie nova. Os vagabundos são o refugo de um mundo que se dedica ao serviço dos turistas (BAUMAN, 1999a, p. 101).

Os vagabundos são aqueles com "tremenda dificuldade" para se adequar à mobilidade exigida na sociedade contemporânea. As "sempre novas" experiências e sensações presentes na leveza da sociedade de consumidores são percebidas como um fardo ainda maior para aqueles que possuem um peso excessivo no próprio corpo, como atesta a fragilidade da mobilidade do vagabundo. Como uma primeira aproximação "entre as metáforas": "Quando além de gordo se é pobre, a dificuldade ganha peso" (SANT'ANNA, 2001, p. 21).

Esta metáfora, ao propiciar o entendimento de uma tipificação, não exclui nossa capacidade de olhar as nuances deste "modelo". A metáfora como uma espécie de "tipo ideal". Assim:

$$
\begin{aligned}
& \text { Estamos todos traçados num contínuo estendi- } \\
& \text { do entre os pólos do 'turista perfeito'e o 'va- } \\
& \text { gabundo incurável' - e os nossos respectivos } \\
& \text { lugares entre os pólos são traçados segundo o } \\
& \text { grau de liberdade que possuímos para esco- } \\
& \text { lher nossos itinerários de vida. A liberdade de } \\
& \text { escolha, eu lhes digo, é de longe, na sociedade } \\
& \text { pós-moderna, o mais essencial entre os fatores } \\
& \text { de estratificação (BAUMAN, 1998, p. 118). }
\end{aligned}
$$

A partir das inquietações lançadas pela metáfora baumaniana $\mathrm{e}$ articulando-a com a nossa preocupação, focaremos a metáfora da obesidade e suas possibilidades em relação ao contemporâneo. Inicialmente, indicamos que algumas questões surgem ao nos deflagrar com esta problemática, dentre elas destacamos: Como a obesidade vem sendo tratada na sociedade contemporânea? Quais os significados da obesidade nesta sociedade? Os argumentos contrários à obe-

Movimento, Porto Alegre, v.12, n. 03, p. 45-71, setembro/dezembro de 2006. 
sidade se baseiam em aspectos eminentemente científicos na área da saúde ou possuem uma conotação moral? Tais questões poderão contribuir para esboçarmos um "diagnóstico" para o "problema".

\section{ASPECTOS DE UM DIAGNÓSTICO SOCIOLÓGICO SOBRE A MODERNIDADE E SUAS "MEDIDAS"}

Sociólogos contemporâneos, como Zygmunt Bauman e Ulrich Beck, apontam diagnósticos semelhantes para caracterizar a atual fase moderna. Com maior ou menor relevância, noções como globalização, risco, individualização, consumo, escolhas e estilos de vida, dentre outras, estão presentes na leitura que esses autores fazem para a compreensão deste mundo. Neste texto, para que possamos alcançar nossos propósitos, faz-se necessário identificar como estes elementos se conectam apontando a obesidade como exemplo daqueles processos.

Beck (1999), ao analisar a globalização, indica a conexão destes elementos citados acima. Para ele, "Globalização significa, diante deste quadro, os processos, em cujo andamento os Estados nacionais vêem a sua soberania, sua identidade, suas redes de comunicação, suas chances de poder e suas orientações sofrerem a interferência cruzada de atores transnacionais" (BECK, 1999, p. 30). Ainda diz que:

Não só [é nova] a vida e a ação cotidiana que ultrapassam as fronteiras do Estado nacional com o auxílio de redes de comunicação interativas e interdependentes; também é nova a consciência desta transnacionalidade (na mídia, no consumo, no turismo); é novo o 'desterramento' da comunidade, do trabalho e do capital; também é nova a consciência global dos riscos ecológicos com seus respectivos campos de atuação; é nova também a ampla percepção do Outro transcultural na própria vida e todas as convicções contraditórias que resultam desta convivência, são novos os terrenos da 
circulação da 'indústria cultural global' (Scott Lash/John Urry); também são novidades o nascimento de um novo modelo europeu de Estado, a quantidade e o poderio de atores, instituições e acordos transnacionais; e é nova também, por fim, a escala de concentração econômica, que, no entanto será freada pela futura concorrência do mercado mundial (BECK, 1999, p. 33).

Para além das discordâncias que possamos ter em relação às “apostas" de Beck (1999), o que nos interessa são aspectos das mudanças sociais contemporâneas que imprimem um novo cenário no qual o indivíduo tem que assumir novas responsabilidades em virtude do declínio do poder decisório do Estado-Nação; por se acelerarem a difusão de modelos através da indústria cultural e suas formas de recepção; bem como os abismos decorrentes das formas de estratificação econômicas na atualidade. Estas características se assemelham ao diagnóstico de Bauman (2001) sobre a "modernidade líquida", ao comentar, por exemplo, em relação à passagem dos "grupos de referência" predeterminados para a "comparação universal"; para o declínio da crença nas metanarrativas; bem como ao referir-se à desregulamentação e a privatização das tarefas e deveres modernizantes (BAUMAN, 2001).

Um outro elemento que permite um diálogo entre estes autores é o conceito de "sociedade de risco" elaborado por Beck (1999, p. 57). Os efeitos colaterais indesejados causados pelos riscos globais rompem com a linearidade e a sensação de ordem presente nos períodos iniciais da modernidade ${ }^{4}$. De certa forma, esta análise coincide com a atual exacerbação das ambivalências descritas

${ }^{4}$ Segundo a teoria da sociedade mundial de risco "[...] já não é mais possível externalizar os efeitos colaterais e os perigos das sociedades industriais desenvolvidas. Em sua condição de riscos de conflito, elas questionam a ordem institucional. Aqui começa a ser desenvolvido um novo pressuposto: o de que os espaços sociais transnacionais também são sustentados por perigos indesejados, negados e reprimidos de forma conflituosa e enigmática, 'pelas costas dos homens' [...] Trata-se de um dinheiro que ninguém quer e que mesmo assim encontra brechas por todas as partes, atraindo, irritando e subvertendo a atenção, virando de ponta-cabeça tudo aquilo que parecia estar apoiado na mais inabalável normalidade (1999, p. 78-79).

Movimento, Porto Alegre, v.12, n. 03, p. 45-71, setembro/dezembro de 2006. 
por Bauman (1999b). Assim, diferentes e contraditórios elementos coexistem nas prateleiras da sociedade contemporânea, rompendo assim com os princípios e tentativas de exclusão típica de uma sociedade estritamente controlada e ordenada, características daquilo que Bauman (2001) denomina de modernidade sólida ${ }^{5}$.

No que Beck apresenta como uma percepção pública dos riscos, Bauman alerta para a responsabilização individual das escolhas. Beck não negligencia o alerta de Bauman, mostrando também que com o processo de individualização crescente "[...] as pessoas têm que encarar como destino pessoal o que antes era visto como destino de classe e atribuir sua falha a si mesmas" (BECK, 1999, p. 265) ${ }^{6}$. De acordo com o autor, os riscos geram insegurança para os indivíduos, pois os defronta com um espaço nebuloso entre as possibilidades de cálculo e o incalculável; desta maneira, permitem "[...] livre acesso à subjetividade para opinar, supor, ter expectativas e esperanças e ter maus presságios" (BECK, 1999, p. 265). Este cenário permite que se amplie os discursos e as práticas baseadas nos estilos de vida individuais. Julia Guivant (2003), utilizando-se do conceito de estilos de vida de Anthony Giddens (2002), diz que "[...] os indivíduos não precisam estar continuamente avaliando suas decisões de consumo, mas estariam cada vez mais conscientes de que estão fazendo uma escolha" (GUIVANT, 2003, p. 2). Jean-Pierre Poulain (2004), ao analisar a "[...] 'desregulação' das práticas alimentares", 7 corrobora com a importância dada às escolhas individuais no contexto contemporâneo. Para Poulain, apoiando-se em Fischler, a alimentação ilustra

${ }^{5}$ De acordo com Bauman: "O fordismo era a autoconsciência da sociedade moderna em sua fase 'pesada', 'volumosa', ou 'imóvel' e 'enraizada', 'sólida'” (BAUMAN, 2001, p. 69). ${ }^{6}$ Bauman $(2001$, p. 43) utiliza-se recorrentemente desta argumentação de Beck ao descrever a modernidade líquida: "Como Beck adequada e pungentemente diz, 'a maneira como se vive torna-se uma solução biográfica das contradições sistêmicas'. Riscos e contradições continuam a ser socialmente produzidos; são apenas o dever e a necessidade de enfrenta-los que estão sendo individualizados".

${ }^{7}$ Esta desregulação "[...] remete para os indivíduos decisões outrora tomadas pelo grupo" (POULAIN, 2004, p. 68).

Movimento, Porto Alegre, v.12, n. 03, p. 45-71, setembro/dezembro de 2006. 
as formas de decisão cotidiana enfrentadas pelos indivíduos.

Mas este processo de individualização não significa que os indivíduos estejam desconectados ou imunes às mudanças sociais. Ao contrário, tais mudanças imprimem o que Beck denomina de "globalização da vida individual", processo pelo qual as escolhas desempenham importante papel ${ }^{8}$. Os indivíduos passam a ter acesso através dos mass media a informações e modelos provenientes de diferentes espaços que fogem às fronteiras do lugar em que vivem. A partir daí, podemos pressupor que imagens e informações sobre a obesidade também se globalizam e passam a influenciar as decisões individuais em diferentes espaços sociais. Valores culturais locais se entremeiam com modelos globais. Daí advém uma questão: a obesidade passa a ser perseguida no globo ou valores locais rompem com a perspectiva sombria dos discursos científicos globais sobre os riscos causados pela obesidade?

Como possível resposta a esta questão podemos dizer que um dos "efeitos colaterais indesejados" apontados por Beck e da "privatização da ambivalência" acentuada por Bauman se configura na preocupação com a obesidade. A sociedade de consumo disponibiliza diferentes oportunidades (mercadorias) que colaboram para a "criação" do obeso, ao mesmo tempo, a obesidade é tratada como "doença" que deve ser combatida. Assim, novas mercadorias são oferecidas aos indivíduos para se prevenirem destes "riscos fabricados". Estes riscos são tratados nas esferas mundiais, como atesta a "estratégia global da OMS - Organização Mundial da Saúde - para dietas, atividade física e saúde" que enfatiza o combate à obesidade e ao sobrepeso9. Caponi, ao comentar o conceito de saúde presente na $\mathrm{OMS}^{10}$, mostra que:

8 Para Beck, (1999, p. 137) "[...] a alternância e a escolha dos espaços são os padrinhos da globalização" para além dos limites do Estado-Nação.

Para maiores informações consultar a página da OMS, mais especificamente o http:// www.who.int/dietphysicalactivity/publications/facts/obesity/en/index.html.

${ }^{10} \mathrm{~A}$ Organização Mundial da Saúde conceitua saúde como "um completo estado de bem-esta físico, mental e social e não meramente a ausência de doença ou de enfermidade" (OMS, 2005)

Movimento, Porto Alegre, v.12, n. 03, p. 45-71, setembro/dezembro de 2006 
[...] Acreditamos que a maior dificuldade deste conceito não se deva a seu caráter utópico e subjetivo, mas somente ao que pode resultar politicamente conveniente para legitimar estratégias de controle e de exclusão de tudo aquilo que consideramos fora do normal, indesejado ou perigoso. A partir do momento em que se afirma o 'bem-estar' como valor (físico, psíquico e social), reconhece-se como pertencente ao âmbito da saúde tudo aquilo que em uma sociedade, e em momento histórico preciso, nós qualificamos de modo positivo (aquilo que produz ou deveria produzir uma sensação de bemestar, aquilo que se inscreve no espaço da normalidade): a laboriosidade, a convivência social, a vida familiar, o controle dos excessos (CAPONI, 2003, p. 130).

Vislumbramos então que a "caça as gorduras" e aos seus portadores não apresenta um porto seguro para estes inaptos. $\mathrm{O}$ risco da obesidade se torna público e globalizado gerando inúmeros conhecimentos e mensagens que transitam em nosso cotidiano. Embora reconheçamos a diversidade de estilos e informações oferecidas na atualidade, nos parece que em relação à obesidade existe uma certa "pressão normativa" no que se refere aos riscos relacionados a ela. Assim, não discordamos do diagnóstico sociológico contemporâneo que afirma existir uma infinidade de critérios disponíveis para as opções efetuadas através das escolhas individuais, apenas entendemos a necessidade de "limitar o seu alcance". Como mostra Poulain (2004, p. 69):

O comedor moderno está submetido, ao mesmo tempo, a uma diminuição da pressão do grupo, da dimensão coletiva da alimentação; ou seja, da obrigação de estar com, e a um aumento de discursos contraditórios no modo do 'é necessário'. A anomia neste caso não remete somente para uma crise do aparelho normativo, mas também para a inflação de injunções contraditórias: higienistas, identitárias, hedonistas, estéticas.

Movimento, Porto Alegre, v.12, n. 03, p. 45-71, setembro/dezembro de 2006. 
Lovisolo (1995) também contribui com esta tese ao apresentar diferentes atores interessados na questão da obesidade como fator de risco e que produzem discursos que podem se conectar em determinadas situações. $\mathrm{O}$ autor destaca entre estes atores sociais o Estado, as empresas seguradoras, a indústria alimentar e os especialistas da saúde. Sobre este último diz que:

Os especialistas da saúde, em especial a classe médica, porém também os educadores fisicos, os fisioterapeutas, os massagistas e outros militam ativamente no campo do movimento pela saúde. Geram discursos e dietas, métodos de emagrecimento, tratamento antifumo, realizam pesquisas para fundamentar sua intervenção [...] Criam clínicas, institutos, academias para práticas esportivas, programas públicos e privados para a realização dos objetivos do movimento: contra a gordura, contra o fumo a favor da atividade corporal. $\mathrm{Na}$ promoção da saúde os especialistas encontraram um campo que lhes permite lutar pelo prestígio na mídia e na moda e fazer bons negócios, protegidos pelo convencimento moral de que estão lutando por uma causa justa e boa (LOVISOLO, 1995, p. 129).

Lovisolo (1995) entende que nos discursos destes atores se entremeiam argumentos técnicos e morais que se articularão com maior ou menor intensidade em função dos contextos e vínculos em que estão inseridos. De uma forma sintética, podemos expor que valores utilitários, estéticos, técnicos, morais elaborados a partir de diferentes instâncias sociais "corporificam" o que entendemos por obesidade, lhe adjetivando de diferentes formas.

Mas apesar deste mosaico descrito anteriormente, entendemos que em relação à obesidade existe um apelo estético ${ }^{11}$ a favor 11 Lovisolo aponta para uma "indiferenciação" entre saúde e estética criada pelos especi-
alistas e outros atores interessados com a questão (LOVISOLO, 1997; 2006).

Movimento, Porto Alegre, v.12, n. 03, p. 45-71, setembro/dezembro de 2006. 
da "boa magreza" que, atrelado ao discurso médico da saúde, limitam o quadro de escolhas. Ou, pelo menos, oferecem riscos demasiados para os que optarem em não se "esforçar atleticamente" para obtenção de medidas "mais estreitas". Fischler (1995), ao analisar a ambivalência do obeso na sociedade contemporânea, aponta que um dos fortes elementos constituintes do imaginário sobre a obesidade indica que "[...] geralmente se está de acordo quando se diz que uma das características de nossa época é sua lipofobia [...] sua rejeição quase maníaca à obesidade: 'A sociedade, como dizia o nutricionista Jean Trémolières, cria os obesos e não os tolera' “(FISCHLER, 1995, p. 69).

No entanto, mesmo para os indivíduos preocupados “em deixar de ser" ou de que "não querem tornar-se" um obeso, o aumento destes discursos contraditórios, principalmente no que se referem às fórmulas dietéticas, causam incertezas frente às estratégias de ação individuais. Como enfatiza Bauman:

O que está em pauta é a questão de considerar e decidir, em face de todos os riscos conhecidos ou meramente adivinhados, quais dos muitos flutuantes e sedutores fins 'ao alcance' (isto é, que podem ser razoavelmente perseguidos) devem ter prioridade - dada a quantidade de meios disponíveis e levando em consideração as infimas chances de sua utilidade duradoura (BAUMAN, 2001, p. 73).

Esta infinidade de possibilidades provenientes de diferentes especialistas apresenta, para Bauman, um guia: o mercado. As escolhas nesta sociedade estão atreladas a capacidade de mobilidade do consumidor. Guivant (2003) alerta também para esta questão:

Tanto Giddens (2002) quanto Beck (1999) tem procurado destacar sociologicamente os significados das crescentes preocupações com a saúde e o bem estar físico frente aos conflitos de posicionamentos dos sistemas peritos. Mas, obviamente, não todas as escolhas estão aber-

Movimento, Porto Alegre, v.12, n. 03, p. 45-71, setembro/dezembro de 2006. 
tas a todos, nem podemos tomas as decisões considerando toda a gama de opções possiveis [...] (GUIVANT, 2003, p. 19).

Estes riscos na área da saúde reforçam a responsabilização individual perante as opções feitas neste emaranhado de discursos. Poulain (2004), utilizando-se de Franck Cochoy, diz que esta difusão de informações constrói uma "habilidade dos consumidores" que "[...] os tranqüiliza, pois lhe dá critérios de escolha, de seleção e de orientação na oferta alimentar, mas, ao mesmo tempo, faz com que eles tenham noção de novas zonas desconhecidas que se tornam fontes de inquietude" (POULAIN, 2004, p. 98). A inquietude e a incerteza contribuem para a lógica da sociedade de consumo. Segundo Bauman (2001, p. 75), “[...] a mais custosa e irritante das tarefas que se pode pôr diante de um consumidor é a necessidade de estabelecer prioridades [...] A infelicidade dos consumidores deriva do excesso e não da falta de escolha. 'Será que utilizei os meios à minha disposição da melhor maneira possível?' [...]". Esta é para Bauman uma das indagações que mais aterrorizam os consumidores contemporâneos e que não se limitam a meras decisões utilitárias. Colin Campbell contribui com esta discussão ao afirmar que:

A lógica cultural da modernidade não é meramente a da racionalidade, como se expressa nas atividades de cálculo e experimentação: é também a da paixão e a do sonhar criativo que nasce do anseio. Todavia, mais crucial do que uma e outra é a tensão gerada entre elas, pois é disso que, afinal de contas, depende o dinamismo do ocidente. A fonte principal de sua inquieta energia não provém apenas da ciência e da tecnologia, nem tampouco da moda, da vanguarda e da boêmia, mas da tensão entre o sonho e a realidade, o prazer e a utilidade (CAMPBELL, 2001, p. 318).

Movimento, Porto Alegre, v.12, n. 03, p. 45-71, setembro/dezembro de 2006 
E é nesta sociedade moderna e em sua atual ênfase no consumo que buscamos analisar os significados da figura do obeso e da obesidade. Como abordado anteriormente, do ponto de vista sociológico, a obesidade se apresenta como um objeto interessante, pois tanto se vincula aos riscos para a saúde constantemente apresentados nos discursos científicos, quanto em relação aos significados sociais da obesidade como uma espécie de "anormalidade" (POULAIN, 2004). São principalmente estes aspectos que abordaremos a seguir.

\title{
3 OBESIDADE E CONSUMO
}

A leveza da modernidade para Bauman (2001) está conectada com a noção de um indivíduo apto. Aptidão no sentido da perpétua disposição para se adequar às mudanças e os novos padrões colocados ao consumidor. Segundo o autor:

\begin{abstract}
O estado de 'aptidão' [...] é tudo menos 'sólido'; não pode, por sua natureza, ser fixado e circunscrito com qualquer precisão. Ainda que muitas vezes tomado como resposta à pergunta 'como você está se sentindo?' (se estou 'apto', provavelmente responderei 'ótimo'), seu verdadeiro teste fica para sempre no futuro: 'estar apto' significa ter um corpo flexivel, absorvente e ajustável, pronto para viver sensações ainda não testadas e impossiveis de descrever de antemão (BAUMAN, 2001, p. 91).
\end{abstract}

Neste sentido, a obesidade e suas pequenas adjacências (as gorduras localizadas) se constituem num dos focos de batalha individual para se alcançar os intermináveis padrões de beleza (intermináveis, embora magros!), enfrentados cotidianamente através das escolhas. Estas escolhas/batalhas podem ser articuladas com o adiamento da satisfação, ou ainda, a valorização das satisfações instantâneas abordadas por Campbell (2001). Estas pequenas e intermináveis guerras cotidianas, mesmo que "prazerosas", estão relacionadas a seguinte afirmação:

O que é característico do moderno hedonismo

Movimento, Porto Alegre, v.12, n. 03, p. 45-71, setembro/dezembro de 2006. 


\begin{abstract}
racional e do comportamento do verdadeiro romântico é a tendência a aproveitar oportunidades para criar desejo, não meramente para satisfazê-lo, e é nisso que o adiamento da verdadeira satisfação se torna essencial. [...] Ela cria [a educação que saliente a satisfação retardada], também, as circunstâncias sob as quais é mais provável que o individuo venha a reconhecer valor na satisfação 'instantânea' (CAMPBELL, 2001, p. 310).
\end{abstract}

Assim, apto não é o indivíduo que vence a batalha (até porque em uma sociedade de consumo ela não poderá ser vencida!), mas aquele que está pronto para novas aventuras, ou em termos baumanianos, para colecionar novas sensações. Novos desejos, novas tecnologias e novos discursos "necessitam/impõem" a predisposição ao não vivenciado. A aptidão é uma atitude perpétua numa sociedade de consumidores (BAUMAN, 2001).

Poulain (2004), de certa maneira, reforça esta idéia da aptidão ao abordar a estigmatização ${ }^{12}$ do obeso nas atuais sociedades modernas, as quais denomina de sociedades desenvolvidas. Afirma, em relação a estigmatização, que:

[...] É no curso de interações sociais que o rótulo de 'excepcional' é atribuido a um indivíduo por outros indivíduos, considerados, estes, 'normais'. Esta etiqueta justifica então uma série de discriminações sociais, até mesmo a exclusão. A estigmatização torna-se um verdadeiro círculo vicioso, quando o obeso aceita e considera como normais os tratamentos discriminatórios que ele sofre e os preconceitos dos quais é vítima. Começa então uma depreciação pessoal que termina numa alteração da imagem de si [...] (POULAIN, 2004, p. 123).

${ }^{12}$ Poulain utiliza-se, dentre outros, do conceito de estigmatização de Cahnman. Para este autor: "Por estigmatização consideramos [...] a rejeição e o desprezo que são associados ao que é visto (a obesidade) como uma deformação física e uma aberração comportamental" (CAHNMAN apud POULAIN 2004, p. 123).

Movimento, Porto Alegre, v.12, n. 03, p. 45-71, setembro/dezembro de 2006. 
O autor ainda completa esta argumentação apontando que o discurso médico contribui neste processo ao "dar ares de neutralidade" científica a esta depreciação vinculada também a outros aspectos sociais ${ }^{13}$. Nas palavras do autor: "A ideologia médica participa da justificação da 'rotulação' como desviante e contribui para a depreciação das pessoas obesas” (POULAIN; 2004, p. 125).

Entendemos que esta depreciação não é exclusividade do obeso, mas este recebe com "maior peso" esta situação. A depreciação se entrelaça com o exame minucioso que os indivíduos se submetem diariamente na busca da aptidão, em outras palavras, na busca do corpo perfeito. Neste contexto, um outro alerta é lançado por Caponi ao frisar que:

[...] A tese de que a experiência do ser vivo inclui a doença, isto é, a idéia de que não existe saúde perfeita, nos fala da ilegitimidade destas políticas da saúde preocupadas em alcançar objetivos impossiveis; talvez descubramos que estas políticas estão mais próximas das estratégias de mercado do que dos efetivos programas de promoção da saúde [...] (CAPONI, 2003, p. 134).

As receitas para obtenção da felicidade através do corpo perfeito insistem na responsabilidade individual. Desta maneira, continuar magro também exige um esforço constante em virtude das novas exigências constantemente criadas e sedutoramente reforçadas. "A busca da 'aptidão' é como garimpar em busca de uma pedra preciosa que não podemos descrever até encontrar [...]”, assim Bauman (2001) remete a este tema para depois arrematar:

${ }^{13}$ Poulain (2004, p. 143-144) levanta uma questão interessante em relação a este aspecto: "Os conhecimentos adquiridos atualmente, tanto sobre os riscos que a obesidade coloca quanto sobre as modalidades de mudar os hábitos alimentares, são suficientemente sólidos para justificar um intervencionismo?"

Movimento, Porto Alegre, v.12, n. 03, p. 45-71, setembro/dezembro de 2006. 
“Uma coisa que os que buscam a 'aptidão' sabem com certeza é que ainda não estão suficientemente aptos, e que devem continuar tentando. A busca da aptidão é um estado de auto-exame minucioso, auto-recriminação e autodepreciação permanentes, e assim também de ansiedade contínua" (BAUMAN, 2001, p. 92-3). Já a depreciação do obeso está vinculada a uma "anormalidade" difícil de extirpar. Desta maneira, um esforço ainda mais intenso é necessário para que o obeso alcance o patamar da "normalidade".

Castro (2003), ao reforçar a importância dos conselheiros neste processo de responsabilização, indica que os obesos são "pressionados moralmente", sendo acusados de falta de "controle de si”. Para a autora:

Os manuais de auto-ajuda, a mídia e os conselhos dos experts em saúde levam os individuos a acreditarem em que as imperfeições e defeitos corporais são resultados da negligência e ausência de cuidado de si. Com disciplina e boa vontade, qualquer um poderia alcançar uma aparência mais próxima do padrão de beleza vigente. Àqueles que não o alcançam é reservada a estigmatização, o desprezo e a falta de oportunidades (CASTRO, 2003, p. 72).

Esta busca por padrões de beleza corporal enfrentada por diferentes atores (entre eles, a indústria farmacêutica, cosmética, alimentícia ${ }^{14}$, as editoras das revistas semanais, os autores de livros de auto-ajuda, os professores de educação física, entre ou-

\footnotetext{
${ }^{14}$ Segundo Guivant (2003, p. 18), "No Brasil, a tendência de consumo de produtos alimentícios identificados como saudáveis tem sido detectada em várias pesquisas de mercado. Entre esses produtos se inclui o segmento chamado diet/light (dietético, leve), que cresce Entre esses produtos se inclui o segmento chamado diet/light (dietético, leve), que cresce
a taxas anuais de $30 \%$ nos últimos anos, segundo dados da Associação Brasileira da a taxas anuais de $30 \%$ nos últimos anos, segundo dados da Associação Brasileira da
Indústria de Alimentos Dietéticos e para Fins Especiais (ABIAD). Segundo ABIAD somente Indústria de Alimentos Dietéticos e para Fins Especiais (ABIAD). Segundo ABIAD somente
as vendas de light e diet corresponderam, em 2001, a cerca de US\$ 1,7 bilhão, dos US\$

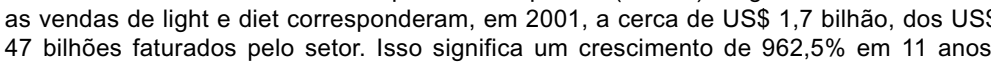
Desde 1990 a média de lançamentos pulou de 40 a 80 por ano" (2003, p. 17). Ainda a mesma autora, citando Revista SuperHiper de junho de 2002, apresenta o seguinte anúncio: “Enfim: sua loja pode 'vender' saúde!" (2003, p. 18).
}

Movimento, Porto Alegre, v.12, n. 03, p. 45-71, setembro/dezembro de 2006. 
tros) estimula mudanças nos próprios índices do que seja o indivíduo "normal". Como alerta Poulain:

O risco é de passar da luta contra a obesidade para a luta contra o sobrepeso e de ver o discurso médico legitimar uma busca obsessiva da magreza. As motivações ostentadas pelas mulheres [e não só delas, mas também dos homens] em restrição cognitiva, ou seja, praticamente um regime alimentar destinado a controlar o ganho de peso, não são motivações de saúde, mas na maioria das vezes de ordem estética (McKie e col., 1993), de sex appeal (Charles e Kerr, 1988), ou, mais geralmente, par 'se sentir melhor' (Basdevant, 1998) [...] E para um grande número dentre elas no ocidente, 'estar de regime', e isso seja quais forem seus pesos reais, faz parte da condição normal da mulher [...] Germov e Williams, num artigo provocativo, pensam que se existe uma epidemia (ou pandemia), é antes uma 'epidemia de estar de regime' (POULAIN, 2004, p. 144).

A obesidade ao ser entendida como fator de risco imprime uma série de previsões futuras e alertas cotidianos. A própria classificação do que é um "obeso" pode sofrer alterações em virtude de pesquisas científicas, como também, das mutações estéticas associadas a contextos sociais e interesses de mercado. Castiel, ao abordar as estimativas de risco, diz que:

[...] É imprescindivel considerar também correspondentes aspectos morais, politicos e culturais. Em especial, cabe destacar a interface com a mídia e a 'indústria da ansiedade, (Forde, 1998) - múltiplos riscos recebem atenção de programas de TV, de materiais de periódicos leigos e a conseqüente oferta de bens, produtos, serviços direcionados ao suposto controle/minimização de tais riscos (CASTIEL, 2003, p. 83).

Movimento, Porto Alegre, v.12, n. 03, p. 45-71, setembro/dezembro de 2006. 
O risco da obesidade permite que sejam elaborados discursos e propostas que visam o futuro. Como declara Paulo Vaz (2001, p. 141) "[...] nossa sociedade é extremamente volátil, pois ela se move ao saber das expectativas [...]". O presente é vivido como mapeamento de riscos que subjazem limites da conduta cotidiana; desta maneira, podemos compreender que as "novas sensações" disponibilizadas aos indivíduos em busca de aptidão também "esclarece" os seus perigos. Esta aposta futura baseada numa "limitação" do presente amplia as possibilidades tanto do campo científico (BRÜSEKE, 2001) quanto de outros indivíduos e instituições envolvidos com a questão da obesidade para propor distintos conselhos que propiciam, de forma geral, o fortalecimento da estigmatização decorrente da estranheza gerada em função das tentativas de "nomeação" deste risco.

Esta estigmatização dos obesos não significa que eles sejam totalmente "desnecessários" no mundo contemporâneo. Em alguns espaços ser obeso não é um problema, como em determinados programas humorísticos (que se utilizam da "silhueta obesa" para fazer rir) ou, como outro exemplo, nas lutas de sumô. Nestes espaços restritos, que contêm um certo "exotismo", a obesidade se constitui numa exigência. Fischler (1995), nesta direção, sustenta que os significados atribuídos às pessoas obesas estão vinculados a sua função social ${ }^{15}$. Para o autor, a obesidade remete a uma violação "simbólica" das regras da divisão social:

Ora, a divisão da comida, na maior parte das sociedades, simboliza a essência mesma do vínculo social. De sorte que o glutão (o obeso, em conseqüência) está implicitamente sob a acusação de ameaçar os próprios fundamentos da

\footnotetext{
${ }^{15}$ Entre as profissões mais vinculadas aos gordos na pesquisa realizada pelo autor encontram-se "[...] os chefes de cozinha, os políticos, os relações públicas, etc. Mais ainda: quando a profissão ou a função do sujeito gordo implicava que ele exercesse um trabalho ligado à força física, certos entrevistados não o viam mais como obeso, e sim como forte"
} (FISCHLER, 1995, p. 73).

Movimento, Porto Alegre, v.12, n. 03, p. 45-71, setembro/dezembro de 2006. 
organização social, o que o remete à animalidade. Nada de espantoso, pois, em se esperar dele uma contrapartida disto que nele vemos em excesso [...] (FISCHLER, 1995, p. 74).

Esta contrapartida ocorre justamente sob a forma de funções sociais que restituem o obeso à coletividade como os "esportistas pesados", os humoristas ou os mascotes de tribos juvenis. Através destas posições o obeso adquire formas de inserção social.

Um outro aspecto se refere à ambivalência do consumo contemporâneo que não negligencia as diferentes "formas" individuais. Todo indivíduo é bem recebido na sociedade de consumo desde que se adeqüe à categoria de consumidor ${ }^{16}$. Sendo assim, são disponibilizadas mercadorias específicas para os obesos nas "gôndolas do hipermercado contemporâneo". Os obesos e a obesidade tornaram-se mais uma fatia a ser explorada e devorada na sociedade de consumo. Essa possibilidade de movimento, embora lento, do obeso consumidor pode ser ilustrada com a seguinte afirmação retirada de uma entrevista concedida por uma consultora de eventos de moda a um site na internet ${ }^{17}$ : "Cada um cuida do seu [biotipo]". Todos são "bem-vindos", entretanto, a mesma consultora lista uma série de posturas e estilos indesejáveis. Podemos então dizer: "Todos são bem-vindos, mas também responsáveis por suas escolhas". Ou na forma de um outro lembrete: "Ser assim - obeso - é de sua inteira responsabilidade".

\section{CONSELHOS CIENTÍFICOS, CONSELHOS MORAIS}

O diagnóstico sociológico no qual estamos nos baseando reconhece a importância das escolhas individuais e da

${ }^{16}$ Como nos relembra Bauman (2001, p. 103): "[...] a alegria e a tristeza do viciado [consumidor] depende de fatores outros que a mera gama de escolhas à disposição. Nem todas elas são realistas; e a proporção de escolhas realistas não é função do número de itens à disposição, mas do volume de recursos à disposição de quem escolhe".

${ }^{17}$ Entrevista concedida por Flavia Viana ao site "brturbo.com.br", acessada em outubro de 2004.

Movimento, Porto Alegre, v.12, n. 03, p. 45-71, setembro/dezembro de 2006. 
"obrigatoriedade" de ter que optar na atualidade. Esta característica da modernidade líquida (BAUMAN, 2001) ou da sociedade de risco (BECK, 1999) tem como parceira a difusão de diferentes instâncias que colaboram para a ampliação do leque de escolhas e suas inerentes contradições. Estamos nos referindo aos infindáveis conselheiros que disponibilizam informações aos indivíduos.

Mas, como visto anteriormente, estas informações chegam de diferentes conselheiros que apresentam interesses distintos, embora possam apresentar "alianças" dentro das relações estabelecidas socialmente ${ }^{18}$. No caso da obesidade, um dos principais conselhos é proveniente do discurso médico. Para Poulain (2004, p. 107):

Os vínculos entre a alimentação e a saúde, mas também entre a alimentação e a doença, são utilizados pelo médico moderno. [...] $O$ desenvolvimento da medicalização da alimentação e a difusão do discurso nutricional científico participam da erosão das dietéticas leigas, apontadas como 'idéias falsas'. Entretanto, a dietética moderna científica é atravessada por correntes teóricas divergentes e encontra-se largamente submetida a efeitos da moda, deixando o comedor num estado de relativa incredulidade.

Esta passagem nos serve como ilustração da tensão que envolve os diferentes conselheiros em relação à obesidade ${ }^{19}$. Em-

\footnotetext{
${ }^{18}$ Beck (1999, p. 58), ao comentar sobre espaços de atuação na globalização, afirma que "Sociedade mundial sem Estado mundial significa uma sociedade que não está politicamente organizada e na qual novas oportunidades de poder e de intervenção surgem para os atores transnacionais, que não possuem a legitimidade democrática. Isto significa a abertura de um novo espaço transnacional da moralidade e da subpolítica, tal como ela se manifesta, por exemplo, nos boicotes de compradores, mas também em questões de comunicação e crítica transcultural". Queremos salientar com esta citação que também surgem na atualidade novos e distintos espaços de comunicação que rompem as fronteiras estatais.

${ }^{19}$ Como outro exemplo ilustrativo deste conflito, vale lembrar que: "Além disso, se a perda de peso tem efeitos positivos imediatos sobre certas patologias associadas à obesidade, como a diabete, até o momento não se fez demonstração de que perder peso inverte a probabilidade de mortalidade" (POULAIN, 2004, p. 143).
}

Movimento, Porto Alegre, v.12, n. 03, p. 45-71, setembro/dezembro de 2006. 
bora exista uma difusão globalizada do combate à obesidade não há um consenso sobre a temática, como apresenta o seguinte trecho: "[...] Associações internacionais se encarregam de propagar os males do sedentarismo e os meios de comunicação são receptivos a essas declarações. Contudo, não são poucos os que relativizam o valor dos resultados das pesquisas, por razões metodológicas e teóricas [...]" (LOVISOLO, 2002, p. 291). Além das divergências discursivas referentes ao conhecimento sobre a obesidade, percebemos outros elementos nesta tensão que se tornam preponderantes e que estão vinculados ao mercado. Os conselhos mercantis aparecem como importante difusor, uma espécie de guru que renova seus conselhos constantemente.

Guivant (2003) contribui com esta discussão ao destacar a relação entre os sistemas peritos (conselheiros) e as escolhas do consumidor. Segundo a autora:

\begin{abstract}
Como Halkier (2001: 208) observa num comentário bastante generalizável, os consumidores podem chegar a ficar preocupados com o que escutam num programa de televisão sobre a pobre qualidade dos alimentos, mas a experiência passa a ser filtrada em alguns poucos dias. Os hábitos de comprar esse determinado alimento se impõem. Os consumidores podem querer melhores alimentos, mas isto pode estar acompanhado com um sentimento de que a informação pública e os desencontros entre sistemas peritos sobre os riscos dos alimentos acabam perturbando a experiência cotidiana de cozinhar e comer (GUIVANT, 2003, p. 20).
\end{abstract}

Bauman (2001), em relação as diferentes formas de conselho, destaca que uma característica que os une é sua restrita área de atuação na esfera privada. Para o autor, os inumeráveis conselheiros transmitem o "[...] que as pessoas aconselhadas podem fazer elas mesmas e para si próprias, cada um para si - não ao que podem realizar em conjunto para cada uma delas, se unirem for-

Wovimento, Porto Alegre, v.12, n. 03, p. 45-71, setembro/dezembro de 2006. 
ças" (BAUMAN, 2001, p. 77). Os esforços que os obesos devem travar para se livrar do "mal" que os acompanha serão árduos, mas restritos a sua própria ação. $\mathrm{O}$ combate à estranheza se concentra no próprio indivíduo, ou como denomina Bauman, é o processo da privatização da ambivalência.

Atrelado a estes conflitos de conselhos (científicos, estéticos, mercadológicos, entre outros), co-existe uma outra espécie de conselho privado em relação à obesidade. Estamos nos referindo a uma espécie de conselho moral. O obeso parece se vincular a um "incômodo social" que se prolifera nas políticas públicas, nas práticas pedagógicas escolares e até nas micro-relações cotidianas. Como mostra Poulain (2004, p. 145), “[...] as fraquezas do nível de prova e de argumentação científica fazem com que muito freqüentemente se misturem, no discurso medicalizado sobre a obesidade, conhecimentos científicos e representações morais". Lovisolo contribui com esta argumentação ao descrever a "moral do autocontrole" enunciada para os obesos. Esta moral enfatiza “[... o] valor da 'mente' ou 'consciência' ou 'superego' em controlar os impulsos (pelos alimentos, estimulantes e inatividade) dos corpos" (LOVISOLO, 1997, p. 13). Fischler (1995, p. 73) aponta na mesma direção ao analisar o imaginário sobre a obesidade: "[...] eles são gordos, pensa-se, porque comem muito e são incapazes de se controlar. De maneira implícita, é, portanto, um julgamento moral que freqüentemente se carrega contra eles". A "perversão moral" dos obesos é combatida pelos conselheiros do corpo saudável como uma missão, sendo "[...] difícil distinguí-la das missões religiosas ou dos movimentos moralizantes" (LOVISOLO, 1995, p. 126) ${ }^{20}$. Este discurso moral da saúde é entremeado por apelos científicos e estéticos que se coadunam com a "privatização

${ }^{20}$ Para o autor, "[...] essas figuras - a do gordo, do inativo e do fumante - não se caracteizam apenas por possuir hábitos que provocam danos à saúde e diminuem as chance de vida, carregam também algum grau de estigma moral, sobretudo quando persistem nessas condutas desajustadas e que, sob o ponto de vista moral, atentariam contra a vida humana [...]" (LOVISOLO, 1995, p. 126).

Movimento, Porto Alegre, v.12, n. 03, p. 45-71, setembro/dezembro de 2006. 
da ambivalência" presente na sociedade de consumidores.

A obesidade e os obesos trazem consigo imagens e significações sociais que as conectam com um lado pesado e lento em contraste com a leveza e a velocidade do mundo contemporâneo. Ser obeso significa, também, uma espécie de inapto, de estranho, de descuidado, de imoral. Em outros termos, parece que os obesos são aqueles que foram nomeados pelos "normais" como o que deve ser extirpado das imagens cotidianas estetizadas para que o mundo se torne mais belo e harmônico. A utopia da saúde perfeita, corrente na atualidade, traz consigo a cruzada contra a obesidade. Como mostra Artur Perrusi:

A obsessão pelas dietas, a compulsão pela malhação, a fobia do colesterol, a obstinação por 'condutas saudáveis' e aprovadas pela medicina, a medicação de qualquer transtorno somático são exemplos, entre outros, apenas superficiais desta utopia - a palavra-chave dessa busca é a compulsão individual e não, como antigamente, um diálogo, uma superação ou uma reafirmação da tradição. O lado velado desse complexo de comportamentos é uma moralidade ou visão do homem - o que, aliás, apenas reafirma o fato de que toda e qualquer utopia guarda consigo uma moralidade - a qual radicaliza, de uma maneira bem singular, o valor supremo da modernidade: o individualismo [...] (PERRUSI, 2001, p. 02).

Para utilizarmos a abordagem baumaniana, este fenômeno remete a "compulsão que é transformada em vício": "Procurar exemplos, conselho e orientação é um vício: quanto mais se procura, mais se precisa e mais se sofre quando privado de novas doses da droga procurada [...]" (BAUMAN, 2001, p. 85). A incessante procura articulada com a entrada das "sempre novas" receitas atormentam, e ao mesmo tempo instigam, o consumidor. Se “[...] o código em que nossa 'política de vida' está escrito deriva da pragmática do comprar" (BAUMAN, 2001, p. 87), então os

Movimento, Porto Alegre, v.12, n. 03, p. 45-71, setembro/dezembro de 2006. 
inaptos desta sociedade têm um fardo a carregar que se expressa nas ações relacionadas aos seus corpos.

\title{
6 A OBESIDADE E O OBESO COMO METÁFORAS CONTEMPORÂNEAS
}

Bauman (1998, 1999a, 1999b, 2005) apresenta diferentes imagens para falar daqueles indivíduos "sobreviventes" nas camadas desprivilegiadas do mundo moderno e que são vistos pelos "de dentro", os incluídos socialmente, como a escória da humanidade. Ele referiu-se aos estranhos para designar, por exemplo, os judeus (as ervas daninhas) na sociedade nazista; chamou de refugo humano aos moradores dos hiper-guetos das metrópoles atuais, bem como os refugiados (os sem Estado); também denominou de vagabundos àqueles que são arrastados pelo constante movimento da sociedade de consumo. Queremos contribuir com estas análises indicando a obesidade (e o obeso) como mais uma destas metáforas contemporâneas.

A obesidade remete à idéia de lentidão e peso, sendo estas características que se distinguem da fluidez atual. Sant'Anna, (2001, p. 19) ao descrever a velocidade contemporânea, alega que isto "[...] cria novas lentidões como se estas fossem somente seus opostos, todo o peso material tendo a ser percebido como mero obstáculo a ser ultrapassado, aniquilado. O peso do corpo é um deles [...]". A obesidade pode representar um empecilho à mobilidade. Esta - a mobilidade - também é apresentada por Beck (1999) como um dos traços característicos da atual modernidade. Para ele:

\begin{abstract}
A mobilidade interna não é, há muito tempo, a exceção, e sim a regra; não é algo desconhecido, mas bastante familiar, que pode recorrentemente ser identificado nas mais diversas formas de expressão; é a conexão contínua entre diversos lugares e suas necessidades sociais especificas, é a segunda natureza da vida individual (BECK, 1999, p. 139).
\end{abstract}

Movimento, Porto Alegre, v.12, n. 03, p. 45-71, setembro/dezembro de 2006. 
A obesidade pode ser enquadrada no que Beck denomina de limites da mobilidade interna ${ }^{21}$. Mas entendemos que a obesidade está além destas limitações físicas. A obesidade como metáfora permite pensarmos a inadequação ao belo numa sociedade que a beleza significa disposição para se adequar às novidades.

O obeso e a obesidade lembram também os pesadelos noturnos que os consumidores aptos temem que possam se concretizar. $\mathrm{O}$ obeso parece ser aquela figura que nos relembra todos os dias que devemos sempre nos esforçar para não ficarmos como ele. Nestes termos, o obeso é aquela espécie de mal necessário, da mesma forma que o vagabundo é para o turista dentro das análises de Bauman (1999a). Assim, o obeso é aquele que deve ser expurgado do nosso cotidiano, pois atrapalha a velocidade cotidiana, torna menos belos os programas de televisivos, entre outras imagens degenerativas. Ao mesmo tempo, o obeso serve como exemplo de inadequação, da falta de iniciativa, mas também lembra aquela forma grotesca que serve de inspiração para piadas infantis ou para transmitirmos momentos de riso a um colega através de mais uma imagem "hilária" enviada pela internet. Ou então, "[...] como se os gordos precisassem compensar o peso do próprio corpo, sendo fiéis produtores de alegria e de consolo [...]" (SANT'ANNA, 2001, p. 21).

Fischler (1995) fala de uma suspeita em relação aos obesos que os tornam ambivalentes, enfatizando que em alguns espaços ou em algumas situações o obeso é "bem-vindo". A obesidade como metáfora, como abordada nesta análise, proporciona uma relação "menos receptiva" ao obeso na atualidade. Reconhece-

${ }^{21}$ Para Beck (1999, p. 139): “[...] A mobilidade interna - diferentemente da externa - significa a medida de flexibilidade física e espiritual necessária ou desejada para o domínio desta vida cotidiana entre mundos diferentes. Aqui se apresentam os limites da mobilidade interna: estas não surgem apenas das dificuldades (financeiras) da coordenação e do controle social cotidiano; elas também são colocadas pela velhice, pela doença e por outros impedimentos".

Movimento, Porto Alegre, v.12, n. 03, p. 45-71, setembro/dezembro de 2006. 
mos estes espaços destacados por Fischler, mas nos parece que a ênfase na contemporaneidade, principalmente no que se refere aos discursos da área da saúde que promovem o corpo saudável, instiga uma cruzada contra estes "excessos", estas ambivalências. Como analisado anteriormente, a obesidade deve ser expurgada privativamente, no entanto, existe uma "eficácia pública" da figura do obeso como lembrança. A lembrança dos vagabundos. Vale ainda salientar como uma situação tipicamente moderna, que quanto mais tenta se extirpar das ambivalências, mais elas são criadas; da mesma forma, a cruzada contra a obesidade gera sempre novos estranhos a serem combatidos - na atualidade, devemos traduzir esta ação como: "combate a ti mesmo!". Não podemos esquecer que os índices das pesquisas sobre obesidade não diminuem, até porque, dentre outros motivos, novos conselhos e medidas são criadas e novos "obesos" ou "indivíduos de risco" são gerados.

Por fim, a sensação é a de que a cruzada contra a obesidade tende a aumentar, seja através das batalhas científicas e mercantis, seja através dos apelos morais. Eis então uma metáfora de um tempo em que a exclusão continua inseparável das análises sociológicas.

Obesity as Contemporary Metaphor: a "Healthy Crusade" on Behalf of Consumption and Risk Abstract: This essay tries an interpretation of contemporary society through the obesity metaphor. We presented it linked with the vagabond's We presented it linked with the vagabond's metaphor formulated by Zygmunt Bauman. The obesity and the obese are analyzed as an ambivalent phenomenon, that therefore contributes for understanding certain forms of actual social exclusion at the present time. The concepts of society of risk by Ulrich Beck and of liquid modernity by Zygmunt Bauman are theoretical foundation for this reflection.

Keywords: Obesity. Metaphor. Social mobility. Social alienation. Postmodernism.

Movimento, Porto Alegre, v.12, n. 03, p. 45-71, setembro/dezembro de 2006. 


\begin{abstract}
La obesidad como metáfora contemporánea: una "cruzada saludable" en nombre del consumo y del riesgo

Resumen: Este ensayo se ubica en las posibilidades de interpretación de la sociedad contemporánea por medio de la metáfora de la obesidad. Presentamos esta metáfora haciendo una vinculación con la del "vagabundo", tal como la ha formulado Zygmunt Bauman. La obesidad y el obeso son analizados como un fenómeno ambivalente, mas que contribuye para la comprensión de determinadas formas de exclusión social en la actualidad. Los conceptos de sociedad de riesgo, de Ulrich Beck, y de modernidad líquida, de Zygmunt Bauman, fueran alicerces teóricos para esta reflexión.

Palabras clave: Obesidad. Metáfora.Movilidad social. Alienación social. Posmodernismo.
\end{abstract}

\title{
REFERÊNCIAS
}

BAUMAN, Z. Modernidade líquida. Rio de Janeiro: Jorge Zahar, 2001.

BAUMAN, Z. Globalização: as conseqüências humanas. Rio de Janeiro: Jorge Zahar, 1999a.

BAUMAN, Z. Modernidade e ambivalência. Rio de Janeiro: Jorge Zahar, 1999b. BAUMAN, $Z$. Turistas e vagabundos: os heróis e as vítimas da pós-modernidade. In: BAUMAN, Z. O mal-estar da pós-modernidade. Rio de Janeiro: Jorge Zahar, 1998. p. 106-120.

BAUMAN, Zygmunt. Vidas desperdiçadas. Rio de Janeiro: Jorge Zahar, 2005.

BECK, U. O que é globalização? Equívocos do globalismo: respostas à globalização. São Paulo: Paz e Terra, 1999.

BRÜSEKE, F. A técnica e os riscos da modernidade. Florianópolis: Ed. da UFSC 2001.

CAMPBELL, C. A ética romântica e o espírito do consumismo moderno. Rio de Janeiro: Rocco, 2001.

CAPONI, S. A saúde como objeto de reflexão filosófica. In: BAGRICHEVSKY, M., PALMA, A.; ESTEVÃO, A. (org.). A saúde em debate na Educação Física. Blumenau: Edibes, 2003. p.115-136.

Wovimento, Porto Alegre, v.12, n. 03, p. 45-71, setembro/dezembro de 2006. 
CASTIEL, L. D. Quem vive mais morre menos? Estilos de riscos e promoção da saúde. In: BAGRICHEVSKY, M., PALMA, A.; ESTEVÃO, A. (org.) A saúde em debate na Educação Física. Blumenau: Edibes, 2003. p. 79-97.

CASTRO, A. L. Culto ao corpo e sociedade: mídia, estilos de vida e cultura de consumo. São Paulo: Annablume: Fapesp, 2003.

FISCHLER, C. Obeso benigno, obeso maligno. In: SANT'ANNA, D.B. (org) Políticas do corpo. São Paulo: Estação Liberdade, 1995. p. 69-80.

GIDDENS, Anthony. Modernidade e identidade. Rio de Janeiro: Jorge Zahar, 2002.

GUIVANT, J. S. Os supermercados na oferta de alimentos orgânicos: apelando ao estilo de vida ego-trip. Ambiente e Sociedade, v. 6, n.2, p. 1-26, 2003. (No prelo) LOVISOLO, H. Esporte e movimento pela saúde: notas de pesquisa. In: LOVISOLO, H. Educação Física: arte da mediação. Rio de Janeiro: Sprint, 1995. p. 109-132. . Da ciência da gastronomia à estética. In: LOVISOLO, H. Estética, esporte e Educação Física. Rio de Janeiro: Sprint, 1997. p. 11-30.

Atividade física e saúde: uma agenda sociológica de pesquisa. In: SIMÕES, R.; MOREIRA, W.W. (org.). Esporte como fator de qualidade de vida. Piracicaba: Ed. da Unimep, 2002. p. 277-296.

Em defesa do modelo JUBESA (juventude, beleza e saúde). In: BAGRICHEVSKY, M., PALMA, A., ESTEVÃO, A., ROS, M. (org) A saúde em debate na Educação Física. Blumenau Nova Letra, 2006. v. 2, p. 157-175.

ORGANIZAÇÃO MUNDIAL DA SAÚDE. Constituição da OMS. Disponível em: < http://www.fd.uc.pt/Cl/CEE/OI/OMS/OMS.htm > Acesso em: 15 jul. 2005.

Global Strategy on Diet, Physical Activity and Health. Disponível em: < http://www.who.int/dietphysicalactivity/publications/facts/obesity/en/index.html> Acesso em: 29 maio 2006.

PERRUSI, A. Utopia da saúde perfeita: a nova ideologia do corpo na modernidade. In: Caos - Revista Eletrônica de Ciências Sociais. João Pessoa, $n^{\circ}$ 3, dezembro de 2001. Disponível em: <http://www.cchla.ufpb.br/caos/03perrusi.html>. Acesso em: 12 de março de 2003.

POULAIN, J. P. Sociologias da alimentação: os comedores e o espaço social alimentar. Florianópolis: Editora da UFSC, 2004.

SANT'ANNA, D.B. Corpos de passagem: ensaios sobre a subjetividade contemporânea. São Paulo: Estação Liberdade, 2001.

VAZ, P. O futuro da genética. In: VILLAÇA, N.; GÓES, F. (org.). Nas fronteiras do contemporâneo: território, identidade, arte, moda, corpo e mídia. Rio de Janeiro: Mauad: FUJB, 2001. p. 137-146.

Recebido em: 30/06/2006

Aprovado em: 08/10/2006

Movimento, Porto Alegre, v.12, n. 03, p. 45-71, setembro/dezembro de 2006. 